\title{
How to Submit Evidence for a Questioned Signature Case
}

Dianne Peterson*

Forensic Document Investigations, Greater Nashville Area, TN, USA

*Corresponding Author: Dianne Peterson, CFDE, Forensic Document Investigations, 370 S. Lowe Ave. Ste. A \#225, Cookeville, TN-38501, USA, Tel: 18887638881; Email: diannefdi@gmail.com

Received date: January 17, 2018; Accepted date: January 23, 2018; Published date: January 29, 2018

Copyright: @ 2018 Peterson D. This is an open-access article distributed under the terms of the Creative Commons Attribution License, which permits unrestricted use, distribution, and reproduction in any medium, provided the original author and source are credited.

Citation: Peterson D (2018) How to Submit Evidence for a Questioned Signature Case. J Forensic Res 9: 410. doi:10.4172/2157-7145.1000410

Keywords: Questioned signature; Forensic document; Traditional mail; Evidence

\section{Opinion}

When preparing a questioned signature case to send to a Forensic Document Examiner here are some important things to remember:

- $\quad$ Try to obtain the original documents if at all possible. Original documents have finer details. If you do not have access to the original documents and the opposing side does, consider requesting them formally with a letter. If the opposing party does not produce them at least you've began a paper trail that they may have to answer as to why they cannot produce the original(s). Sometimes both parties can agree on having the original documents examined with both of them present in the same room. However, this can be more expensive but has been proven to be worth it.

- If you can only obtain photocopies, make sure they are the best resolution possible before sending them to your document examiner. It is preferred that they are scanned and photocopied at least 300-600dpi (dots per square inch). It is also preferred to have a first generation photocopy (a scan taken directly from the original). The more times a document is photocopied the resolution will continue to deteriorate.

- Send documents electronically and by traditional mail. This way if a document(s) gets lost in the mail you will at least have it stored electronically.

- When scanning documents make sure you scan the entire page of the document, not just the signature portion. Document examiners need to source where each signature is taken from.

- When examining questioned signature cases it is ideal to have up to 20 comparison signatures. It is possible to render an opinion with less comparison signatures, but make sure you've exhausted all sources before the case is sent. The best evidence will render the best results in the case.

- Do not let your client write on any of the documents.

- Group the questioned documents and the comparison documents separately. When sending them by mail, paperclip them and place a sticky note identifying the documents as the questioned or comparison documents. When sending them electronically, identify them by labeling the PDF (Portable Document Format) separately.

- In some cases requested handwriting samples can help identify the author of he questioned signature. Request handwriting samples are performed in a very specific way and does not constitute that someone sits down and starts writing their own name numerous times. Your document examiner will take the request writing or give you detailed instructions on how to gather it.

- Even though document examiners are hired $90-95 \%$ of the time to examine signatures in questioned; we still examine the entire document to reveal any alterations, additions or deletions, erasures, obliterations and altered numbers.

- If a potential client thinks someone may have copied and pasted a signature from another document ask them if might be able to produce that document.

- All document examiners reserve the right to change their opinion if new evidence is entered into a case at any time. So make sure you attain the best possible evidence before you send it to your document examiner. 